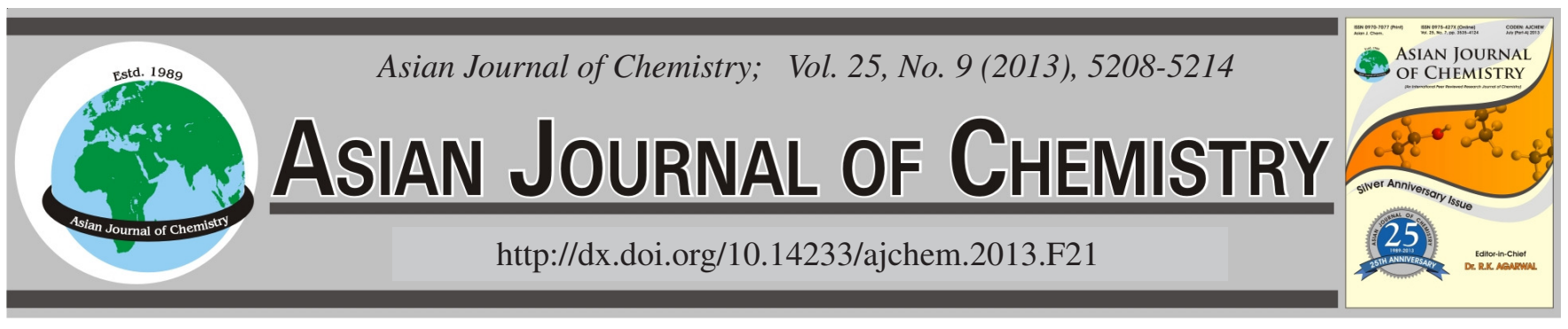

\title{
Design Concept of Tread Compound for Cutting and Chipping Resistance of Truck Tyres on On/Off the Roads $\dagger$
}

\author{
Byung-Ho Park ${ }^{*}$, Dong-Ho Chang, Han-SeOK Song, IL-TAik Jung and Choon-Tack Cho
}

KUMHO TIRE R \& D Center, 555 Sochon-Dong, Kwangsan-ku, Kwangju, Republic of Korea

*Corresponding author: Fax: +82 62950 4199; Tel: +82 62950 4228; E-mail: bhpark@kumhotire.com

Truck tyres, running on and off roads at the same time, commonly observed normal fatigue wear in the initial stages followed by abrasive | wear and cutting and chipping later. This study examined many factors that could maintain the initial wear characteristics but prevent cutting and chipping problems on the tread compound of a truck tyre. The physical properties, polymer blends in terms of composition natural rubber base, NR/SBR blend and NR/BR blends, the role of silica in the carbon black base and cure system were investigated. The results showed that it is important to apply the appropriate compound for the actual operating conditions because of the mutual inverse relationship between the wear characteristics and cut and chip properties. The $300 \%$ stress must be at least $90 \mathrm{kgf} / \mathrm{cm}^{2}$ but below $135 \mathrm{kgf} /$ $\mathrm{cm}^{2}$ to prevent blow out as well as provide cut and chip resistance. If $300 \%$ stress is below $90 \mathrm{kgf} / \mathrm{cm}^{2}$, tread compound exhibits low abrasion resistance and frequently experiences blow out under severe conditions. On the other hand, compounds exhibiting a $300 \%$ stress above $145 \mathrm{kgf} / \mathrm{cm}^{2}$ exhibited good fatigue abrasion but poor cut and chip characteristics. In addition to the physical properties, the polymer blend, the cure system and silica loading in a black filled system also showed a trade-off relationship regarding normal abrasion and cutting and chipping resistance.

Key Words: Cutting and chipping resistance, Off-the road, Tread, Silica, Cure system.

\section{INTRODUCTION}

Historically tyres had performance trade-offs that improve the performance. Truck tyres, running on and off roads at the same time normally show normal fa tigue wear in the early followed by abrasive wear, cutting and chipping in later stages. The understanding of these relationships and controlling them is important for improving the wear properties.

Hundreds of materials can be used in tyres. The appropriate combination of materials for the specific application intended is needed when choosing the correct tyre compounder. When developing tyre compounds for good abrasive properties, the main materials with the most effect include polymers, fillers and the cure systems. The type of polymer or the use of its blends in tread compounds helps improve the wear properties significantly. The primary types are natural rubber, butadiene rubber and SBR, which is a rubber consisting of styrene and butadiene ${ }^{1}$. A higher butadiene content in a polymer system results in better wear resistance due to the low friction energy ${ }^{2,3}$. On the other hand, these approaches will have a negative effects on the failure properties, such as the abrasive wear, tensile strength and road hazard damage ${ }^{4}$. The other important materials include the filler, which interacts with the polymer. The primary types of fillers used in tyres are carbon black and silica $^{5}$. Using high structure carbon black with a low particle size results in better wear resistance. Although carbon black is used predominantly in tyres, the use of silica has become a primary alternative to improving the crack resistance. The cure systems are the final component in a tyre compound for improving the chipping resistance. When heated together with the polymer, filler and other additive agent including curing agent, it forms insoluble cross-links, tying everything together into a solid, elastic rubber tyre compound. These cross-links are generally derived from sulfur. The number of sulfur atoms contained in the crosslink also affects the crack and abrasion properties $^{6}$. When considering the crack propagation and chipping resistance, compounds with longer sulfur chains in the compound are generally better than low sulfur contents, i.e. 1 or 2 atoms. In addition, determining the best way to cure a tyre (time and temperature) or how to mix the compounds can improve the physical properties. The interaction among all these components produce good wear performance under operating conditions, which is defined by driving speed, road conditions, such as on/off road, temperature, loading capacity 
etc. The aim of this study was to design a compounding concept, which is related to the physical properties, types of polymer blend, optimum amount of silica loading in the black filled system and the cure system for overcoming the tradeoff properties of normal abrasion and cutting and chipping resistance. The other is to improve the cutting and chipping resistance without adversely affecting the tyre wear resistance of the tread compound in truck and bus tyres.

\section{EXPERIMENTAL}

The rubber compounds used were general compounds that are similar to the formulation used for the truck and bus radial tread. The test formulation is based on the blends of NR, BR and SBR including the fillers and CZ/S cure systems. All the compounds were prepared using a two-step process that included the preparation of a master-batch in a $1600 \mathrm{~mL} \mathrm{BR}$ Banbary mixer, followed by curative addition in the mixer. The fill factor was $0.73 \sim 75$. The optimum cure time at $145^{\circ} \mathrm{C}$ was determined as the time to reach maximum torque using the oscillating disc Monsanto Rheometer curves. Vulcanized sheets were prepared by molding in a heated press at $145^{\circ} \mathrm{C}$. Test methods, such as the stress strain test, heat build-up and blow-out, were performed using ASTM test methods. For the edge cut test, tensile strips were cut from the vulcanized sheets using a die (15.5 mm wide and $150 \mathrm{~mm}$ length) (Fig. 1). The pre-cut of the sample was introduced perpendicular to the specimen length at the midpoint edge using a razor blade, which had been dipped in a soap solution. The depth of an edge cut was determined by travelling microscopy. Cut growth testing was carried out using Instron testing machines. The specimens were extended at a strain rate of $0.833 \mathrm{~min}^{-1}$. (Cross head speed $=50 \mathrm{~mm} / \mathrm{min}$ and initial grip distance $=60 \mathrm{~mm}$ ) to failure. To analyze the effect of a pre-cut on the tensile properties of carbon black/silica filled samples, the tearing energy were obtained from eqn. $(1)^{7}$.

$$
\mathrm{T}=2 \mathrm{~K} \mathrm{~W}_{\mathrm{b}} \mathrm{C}
$$

where $\mathrm{T}$ is the tearing energy of sample specimen, $\mathrm{W}_{\mathrm{b}}$ is the strain energy density, which was measured from the areas under the stress-strain curves corresponding to the strain of the precut specimen, $\mathrm{C}$ is the crack length and $\mathrm{K}$ is a dimensional parameter that approaches $\pi$ at very small strain and decreases slowly with increasing strain $\left(\cong \pi / \lambda^{1 / 2}, \lambda\right.$ is the extension ratio in the body of the test piece).

\section{RESULTS AND DISCUSSION}

Required physical properties of the tread compound for truck tyre: Less heat under load, less heat to enhance the tyre durability and fatigue life are necessary conditions for truck and bus radial tyres. The heat build-up is strongly dependent on the stress of the tread compounds at a $300 \%$ extension ratio as well as the blow out properties (Figs. 2 and 3 ). The $300 \%$ stress must be at least $90 \mathrm{kgf} / \mathrm{cm}^{2}$ to prevent the high heat build-up in the compound. Table- 1 suggests that if the $300 \%$ stress is below $90 \mathrm{kgf} / \mathrm{cm}^{2}$, the tread compound exhibits low abrasion resistance. On the other hand, the compounds exhibiting a $300 \%$ stress $>145 \mathrm{kgf} / \mathrm{cm}^{2}$ exhibited good abrasion resistance but significantly lower crack resistance as shown in Table-2. This indicates that the wear resistance and blow out properties can be improved by making tread compounds stiffer through a compounding design improves, but cutting and chipping resistance is reduced. Specifically, the required value of $300 \%$ stress of the tread compound should be between $90 \mathrm{kgf} / \mathrm{cm}^{2}$ and $135 \mathrm{kgf} / \mathrm{cm}^{2}$ for an un-paved road. This provides good cutting and chipping resistance whilst maintaining the blow-out properties and minimizes fatigue wear resistance. On the other hand, The $300 \%$ stress of the tread compound for a paved road should be between 135 to $165 \mathrm{~kg} / \mathrm{cm}^{2}$ for good wear resistance. If the $300 \%$ stress is $>165 \mathrm{kgf} / \mathrm{cm}^{2}$, the tread area of the truck tyre showed good fatigue wear in the initial stages but cutting and chipping can occur easily if run on and off the roads at the same time.

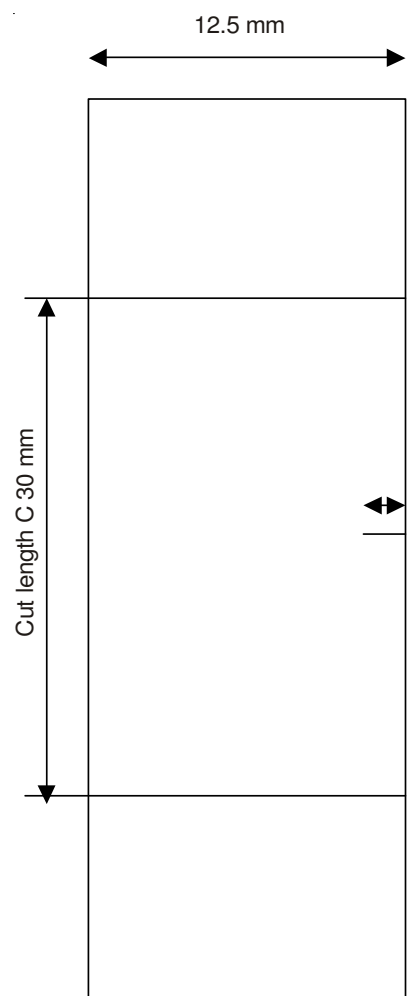

Fig. 1. Strip tensile specimens with an edge cut of length, $\mathrm{C}$

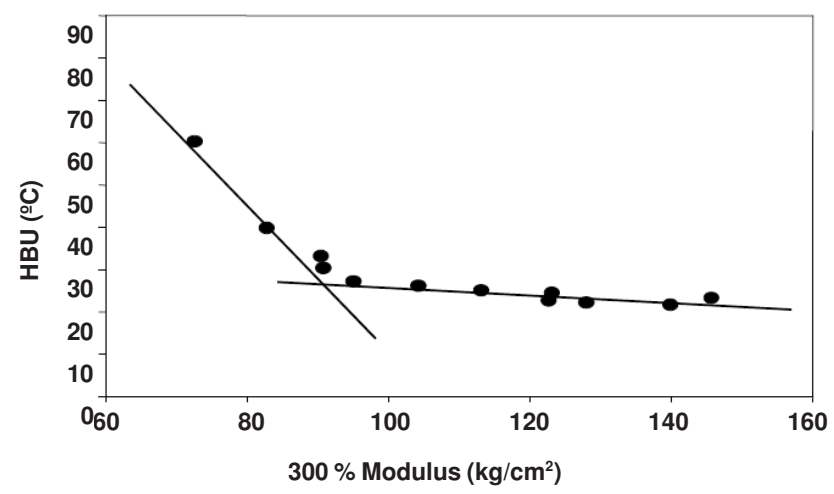

Fig. 2. Relationship between the $300 \%$ modulus and heat build-up (HBU)

Effects of polymer blend systems: The polymer types or their blends of tread compounds of a tyre help improve the wear properties significantly ${ }^{2,3}$. The primary polymer types of the truck and bus radial tread compounds are natural rubber, butadiene rubber and SBR. Fig. 4 shows that the NR-based 


\begin{tabular}{|c|c|c|c|c|c|c|}
\hline \multicolumn{7}{|c|}{$\begin{array}{l}\text { TABLE-1 } \\
\text { COMPARISON OF RELATIVE ABRASION RESISTANCE WITH DIFFERENT STRESSES } \\
\text { AT } 300 \% \text { EXTENSION ON VARIOUS RUBBER COMPOSITIONS }\end{array}$} \\
\hline Polymer base & Stress at $300 \%, \mathrm{kgf} / \mathrm{cm}^{2}$ & On paved road (\%) & On non-paved road (\%) & Cut \& chip test $(\%)$ & DIN test $(\%)$ & PICO test (\%) \\
\hline NR $100 \%$ & $95^{*}$ & 93 & 129 & 100.7 & 48 & 62.3 \\
\hline NR $100 \%$ & 126 & 96 & 101 & 94.8 & 103 & 96.7 \\
\hline NR $100 \%$ & 145 & 100 & 100 & 100 & 100 & 100 \\
\hline $\mathrm{NR} / \mathrm{BR}=60 / 40$ & 165 & 112 & 94 & 65.1 & 158 & 128 \\
\hline NR $100 \%$ & 152 & 108 & 93 & 109 & 103 & 101 \\
\hline NR $100 \%$ & $128^{*}$ & 112 & 128 & 128 & 89.3 & 78.7 \\
\hline
\end{tabular}

compound exhibited well developed secondary cracks, which are related to knotty tearing on the crack passage. On the other hand, NR/SBR and NR/BR based compounds showed a relatively simple crack path with a large secondary crack. The failure properties and fatigue results from Table- 2 showed that a $100 \%$ NR-based compound exhibited better failure properties and fatigue crack resistance than that of the NR/BR or NR SBR blend systems. This means that a NR/BR-based compound can easily provide chipping and chunking resistance because of the low fatigue resistance compared to that of the NR based compound. The greater use of butadiene rubber in polymer blends resulted in better abrasion resistance if considering the abrasion properties, such as DIN and PICO.

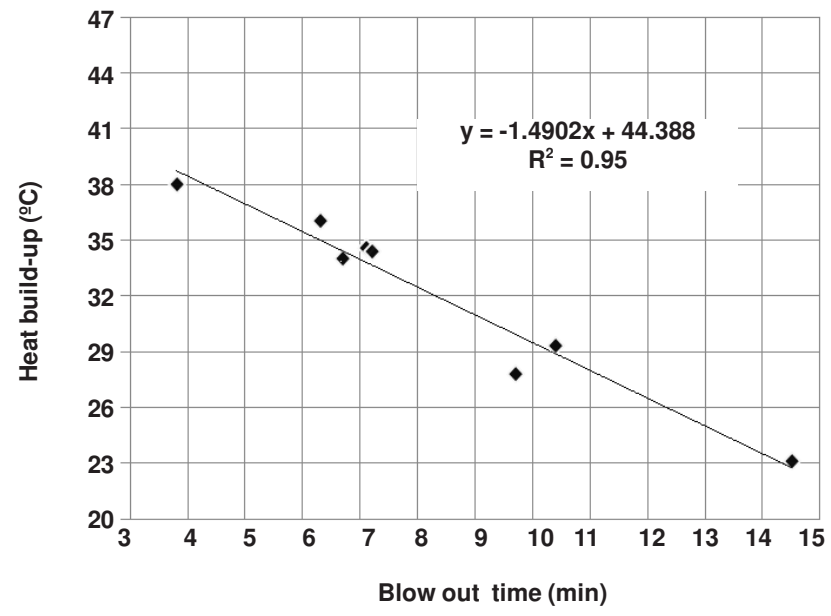

Fig. 3. The relationship between the heat build-up and blow-out time

\begin{tabular}{|c|c|c|c|c|}
\hline \multicolumn{5}{|c|}{$\begin{array}{c}\text { TABLE-2 } \\
\text { COMPARISON OF THE PHYSICAL PROPERTIES WITH } \\
\text { VARIOUS STRESSES AT } 300 \% \text { EXTENSION } \\
\text { ON VARIOUS RUBBER COMPOSITIONS }\end{array}$} \\
\hline Polymer base & $\begin{array}{l}300 \% \\
\text { modulus } \\
\left(\mathrm{kgf} / \mathrm{cm}^{2}\right)\end{array}$ & $\begin{array}{l}\text { Crack } \\
\text { growth rate } \\
\left(\mathrm{dC} / \mathrm{dn}^{* *}\right)\end{array}$ & $\begin{array}{c}\text { Strain energy } \\
\text { density } \\
\left(\mathrm{kgf} / \mathrm{cm}^{2}\right)\end{array}$ & $\begin{array}{c}\text { Tear } \\
\text { energy } \\
\left(\mathrm{kgf} / \mathrm{cm}^{2}\right) \\
\end{array}$ \\
\hline NR $100 \% *$ & 95 & 1.08 & 788 & 77.8 \\
\hline NR $100 \%$ & 126 & 1.29 & 753 & 62.4 \\
\hline NR $100 \%$ & 145 & 1.30 & 835 & 65.2 \\
\hline $\mathrm{NR} / \mathrm{BR}=60 / 40$ & 165 & 1.70 & 617 & 32.1 \\
\hline NR $100 \%$ & 152 & 1.41 & 799 & 62.1 \\
\hline NR $100 \% *$ & 128 & 1.02 & 767 & 75.3 \\
\hline
\end{tabular}

Overall, the wear characteristics are changed by the types of polymer blends. The wear properties of a tyre on a paved road are affected by the frictional energy by the load and speed.
Therefore, the recommended polymer base is the NR or the NR/ BR base. On the other hand, a tyre subjected to an unpaved road requires good failure properties and abrasive resistance. The recommended polymer base of the tread compound for on \& off road tyres is NR based for excellent fatigue $\&$ failure properties under harsh conditions and NR/SBR blend for good cutting resistance under low severity conditions.

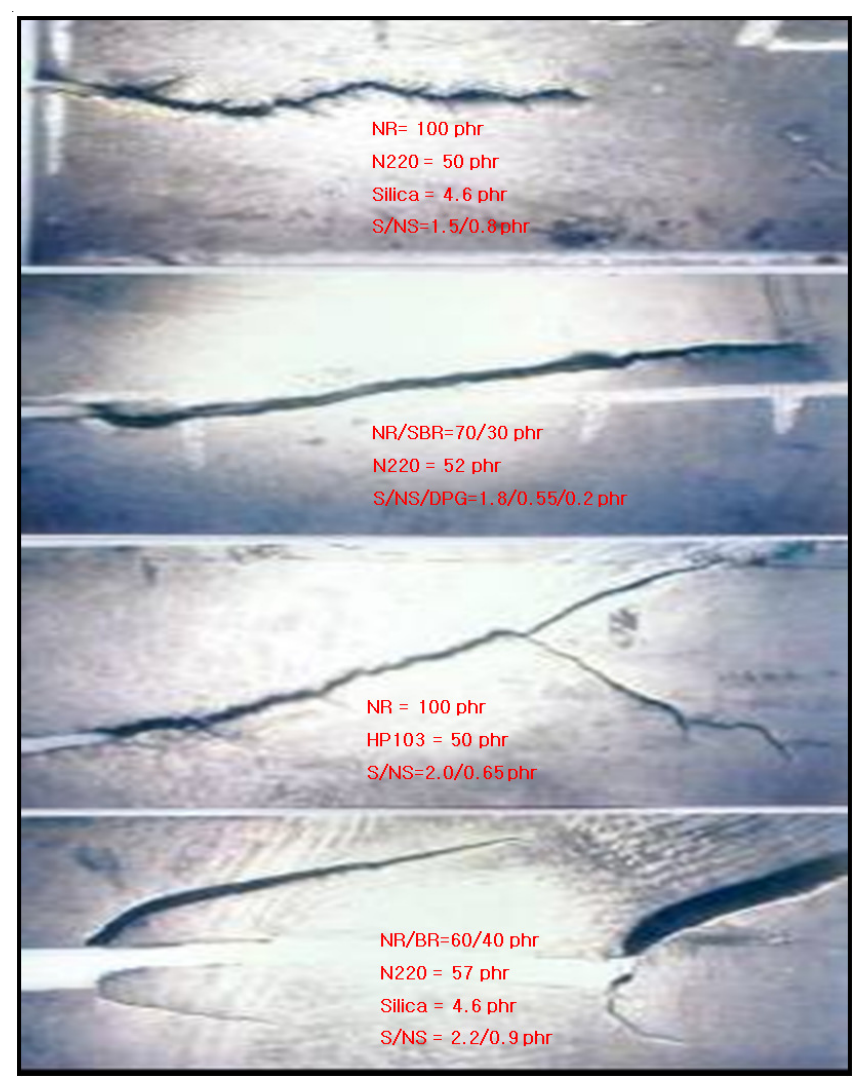

Fig. 4. Optical micrographs of the crack path for various compositions of NR, NR/SBR and NR/BR blend systems

Effects of the silica loading in a carbon black-filled tread compound: The tensile strength was measured for silica/ black filled specimens containing range of pre-cut sizes (C). Fig. 5 shows the relationship between the tensile strength and pre-cut size. All compositions exhibited a critical cut-size $\left(\mathrm{C}_{\mathrm{cr}}\right)$, which was related to an abrupt decrease in tensile strength. Interestingly, the tensile strength reached a maximum silica content of $10 \mathrm{phr}$ and then decreased gradually with increasing silica content when $\mathrm{C}<\mathrm{C}_{\mathrm{cr}}$. For example, $10 \mathrm{phr}$ silica-filled specimen provided higher tensile strength $\left(151.3 \mathrm{~kg} / \mathrm{cm}^{2}\right)$ than the $40 \mathrm{phr}$ silica-filled specimens $\left(97.5 \mathrm{~kg} / \mathrm{cm}^{2}\right)$, as shown in 

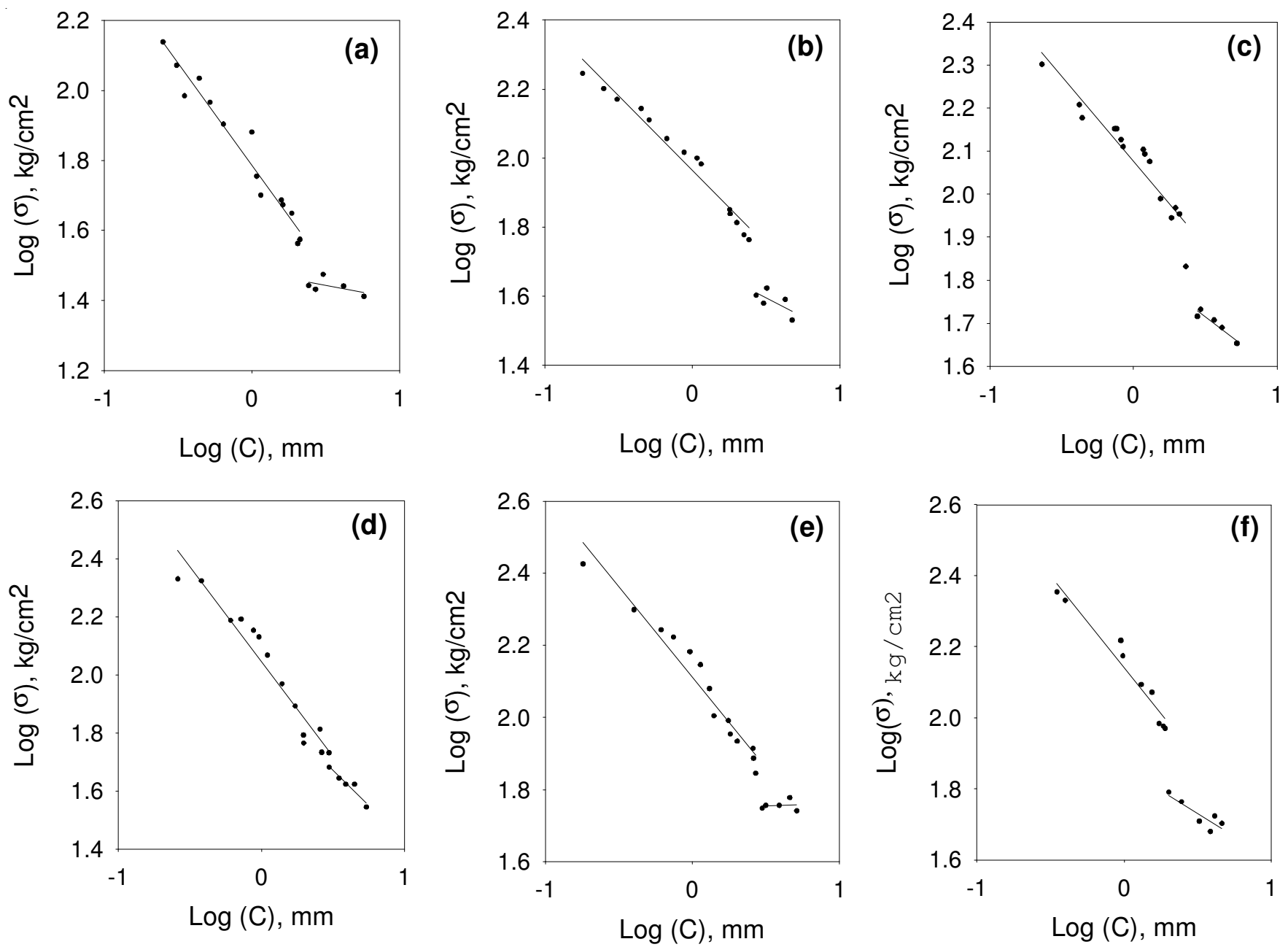

Fig. 5. Effects of pre-cut size on the tensile strength for various silica/carbon (S/C) ratio in NR 100 based TBR tread compounds. (a) 50/0, (b) 40/10, (c) $30 / 20$, (d) $20 / 30$, (e) $10 / 40$, (f) $0 / 50$

Figs. 6 and 7. The low silica filled (10 phr) specimen exhibited a deflected crack with multiple secondary cracks. On the other hand, the high filled silica (40 phr) specimen showed deflected cracks with simply developed secondary cracks at the tip region. High tensile strength was observed with multiple delaminated-cracks before catastrophic tearing and longer diagonal crack deflection. As explained by Hamed ${ }^{8,9}$, crack deviation at the crack tip was responsible for the enhanced tensile strength. One of the possible schemes is that both the high orientations due to chain slippage over the silica surface and strands formed from strong interactions between the carbon black and rubber matrix appear to be associated with extensive longitudinal cracks at the tip region. The slippage behaviour of the polymer chain on the silica surface depends on the quantity of silica used. At low concentrations $(<20 \mathrm{phr}$ silica), the low interaction between the polymer and silica is related to the enhanced orientation at the tip region during the stretching. On the other hand, at higher concentrations (i.e., > $20 \mathrm{phr}$ silica), the stress at the tip might be too low to induce the sufficient alignment of polymer chains because of the obstacle of chain configuration due to the large silica particles. In addition, the low interaction between silica and rubber molecular induces slip over of the filler surface and a failure to drag it into alignment. Fig. 8 shows the effect of the silica loading on the critical cut size. Some limits were encountered

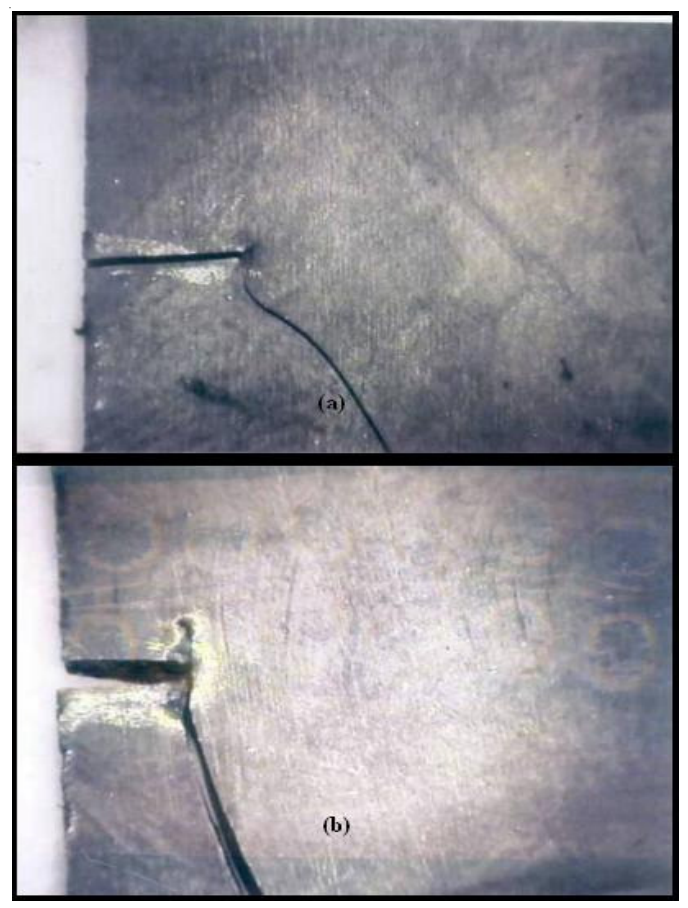

Fig. 6. Optical micrographs for the region near the crack tip. (a) silica/ carbon $=10 / 40: \mathrm{C}=0.96 \mathrm{~mm} ; \mathrm{s}=151.3 \mathrm{~kg} / \mathrm{cm}^{2}, \mathrm{TE}=54.9 \mathrm{~kJ} / \mathrm{m}^{2}$, (b) silica/carbon $=40 / 10: \mathrm{C}=1.16 \mathrm{~mm} ; \mathrm{s}=97.5 \mathrm{~kg} / \mathrm{cm}^{2}, \mathrm{TE}=45.1$ $\mathrm{kJ} / \mathrm{m}^{2}$ 


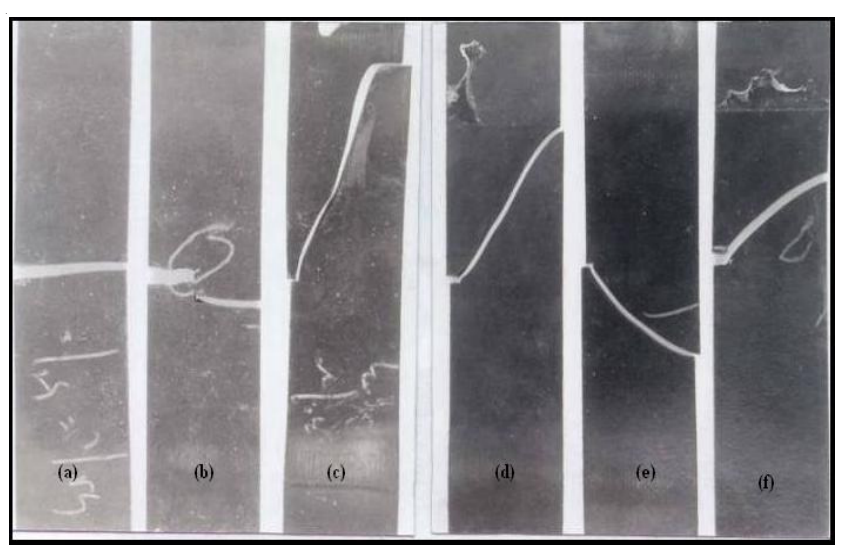

Fig. 7. Optical micrographs of the crack paths for various silica/carbon (S/ C) ratio in NR 100 based TBR tread compounds. (a) 50/0, (b) 40/ 10 , (c) $30 / 20$, (d) $20 / 30$, (e) $10 / 40$, (f) $0 / 50$

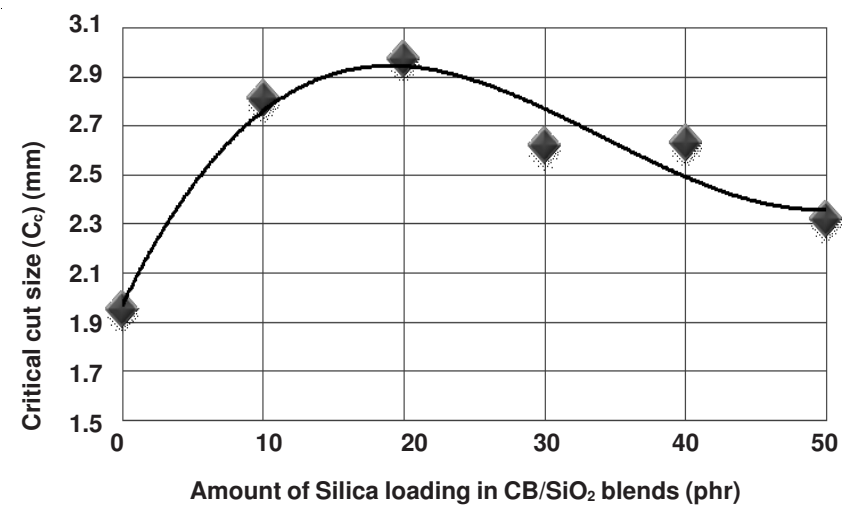

Fig. 8. Critical cut sizes as a function of the silica content for silica/N330 filled vulcanizates

when calculating the precise critical cut size according to the silica loading because the tensile strength of the pre-cut sample is closely related to the crack tip pattern. The critical cut size for NR is in the range, $1.95 \mathrm{~mm}$ to $2.97 \mathrm{~mm}$ and the variation of silica loading affects the critical cut size. The maximum point of the critical cut size appears to be somewhere between a silica loading of $10 \mathrm{phr}$ and $30 \mathrm{phr}$ in the black-filled compound, which then decreases gradually with further increases in silica loading.

Fig. 9 presents the intrinsic cut-size as a function of the silica content for the silica/carbon black-filled NR vulcanizates. All specimens have naturally occurring flaws, entrapped impurities or edge flaws introduced by the cutter. The intrinsic cut-size was obtained from an extrapolation to the tensile strength when an intentional pre-cut was not present. The physical meaning of $\mathrm{C}_{\mathrm{o}}$ is that an actual razor cut with a length less than $\mathrm{C}_{\mathrm{o}}$ would have no effect on the strength, whereas, a razor cut length longer than $\mathrm{C}_{\mathrm{o}}$ would reduce the strength ${ }^{10}$. The inherent flaw size exhibited some variations, $243 \mu \mathrm{m}$ for only carbon black (silica content: 0 phr) filled compound, 219 $\mu \mathrm{m}$ for silica $10 \mathrm{phr}$ and $222 \mu \mathrm{m}$ for the silica $20 \mathrm{phr}$ filled compound. On the other hand, an abrupt decrease in the intrinsic flaw size to $103 \mu \mathrm{m}$ and $74 \mu \mathrm{m}$ was observed for silica $30 \mathrm{phr}$ only silica filled compound, respectively. The significance of the decrease in $\mathrm{C}_{\mathrm{o}}$ with increasing silica content was a high silica content in the compound with a low ability to tolerate the flaws before catastrophic tearing. On the other hand, the higher $\mathrm{C}_{\mathrm{o}}$ value for black-filled rubber or for a low silica content indicates the greater ability to blunt the crack tip before catastrophic failure and hence delay fracture. This means that a lower filler-polymer interaction that facilitates filler flocculation in high loading silica compounds would result in a low intrinsic flaw size. Overall, a small amount of silica, $<20 \mathrm{phr}$, in the black filled compound can improve the cutting and chipping resistance because it increases the resistance of crack propagation after cutting and exhibits a higher critical cut size compared to a carbon black filled compound. This also provides a high intrinsic cut size compared to the material with a high silica loading.

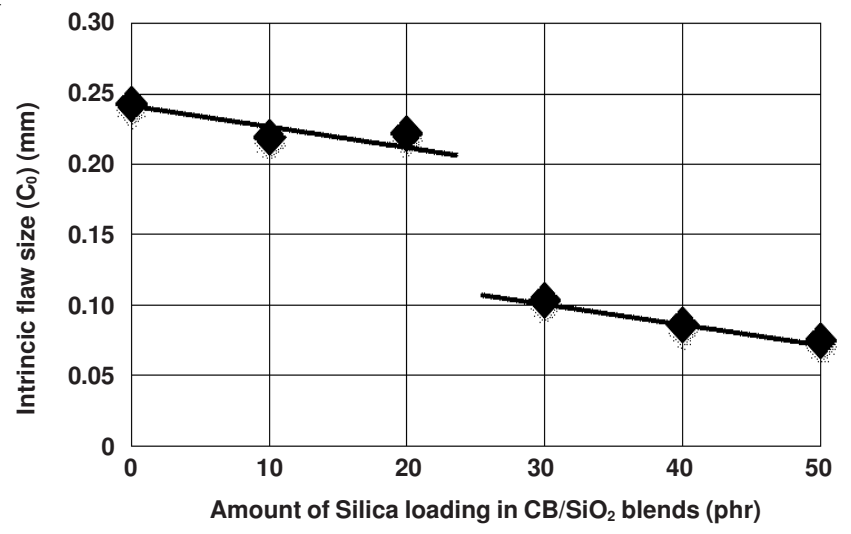

Fig. 9. Intrinsic flaw size against the silica contents for silica/N330 filled vulcanizates

Cure system effects: Many types of cure systems are used for tyre compounds. In the tyre industry, the generally accepted cure systems include conventional vulcanization-system (CV), semi-efficient vulcanization (semi-EV) and hybrid cure system, which contained alkyl sulfide bond among polymer chains ${ }^{11}$. Figs. 10 and 11 show that the $\mathrm{CV}$ system, which contain mainly poly-sulfidic cross-links, has high tensile and tensile strength compared to semi-EV or EV cured rubber, which contains a high proportion of monosulfidic covalent linkages. Polysulfidic cross-links can rearrange under stress but mono-sulfide or carbon-carbon bonds cannot exchange and rearrange. Fig. 12 exhibits a crack growth pattern under the condition of repeated strain condition. The CV sample showed a well developed secondary crack but the EV system

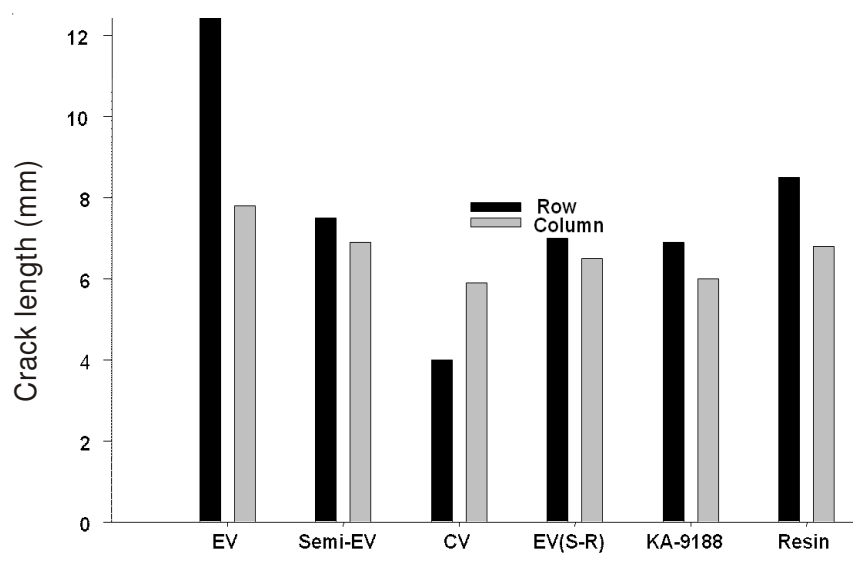

Fig. 10. Comparison of the DMFC test results with varying curing systems under equal hardness 
적합선 플롯

QUT $/ \mathrm{CHP}=90,34+14,52 \mathrm{~S} / \mathrm{NS}$ ratio

$-5,223$ S/NSratio $* 2$

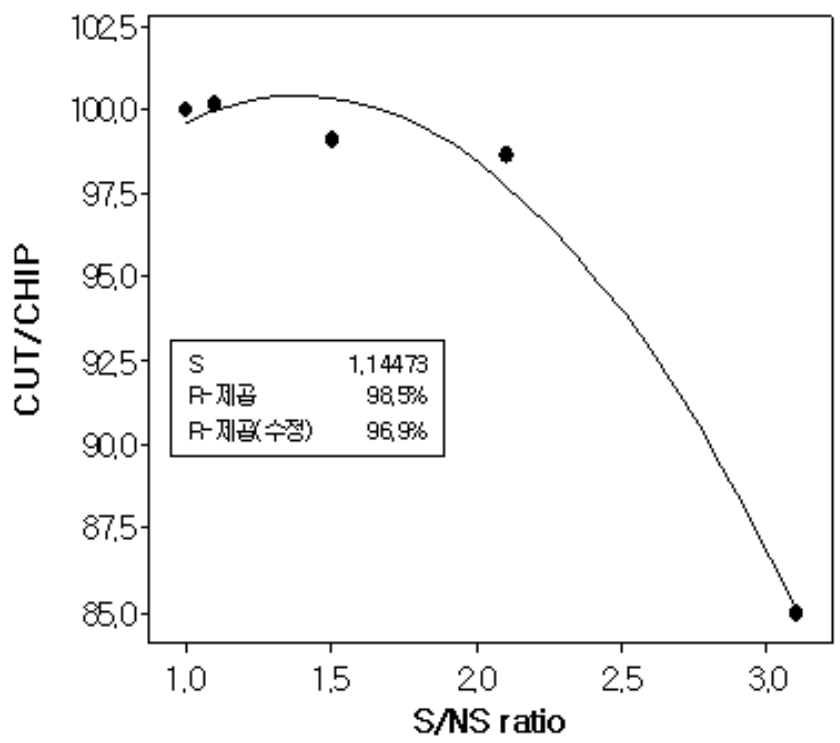

적흡선 플롯

$\mathrm{DNN}=90,28+1,5 \mathrm{~S} / \mathrm{NS}$ ratio

$+6,202 S / N S$ ratio $* 2$

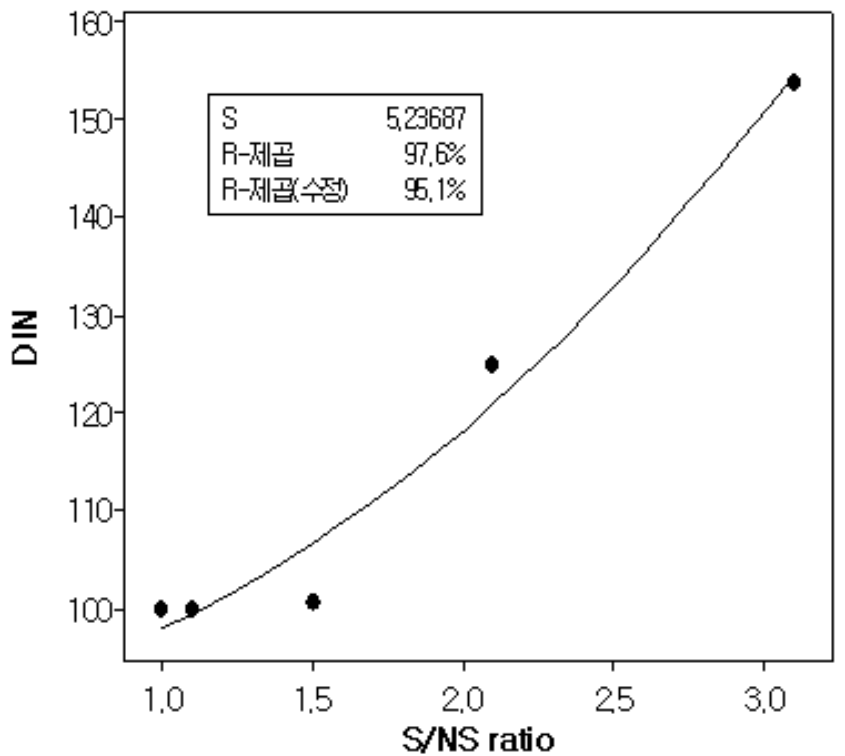

적합선 플롯

$\mathrm{T} . \mathrm{S}=108.2-11.06 \mathrm{~S} / \mathrm{NS}$ ratio

+3.648 S/NS ratio $*+2$

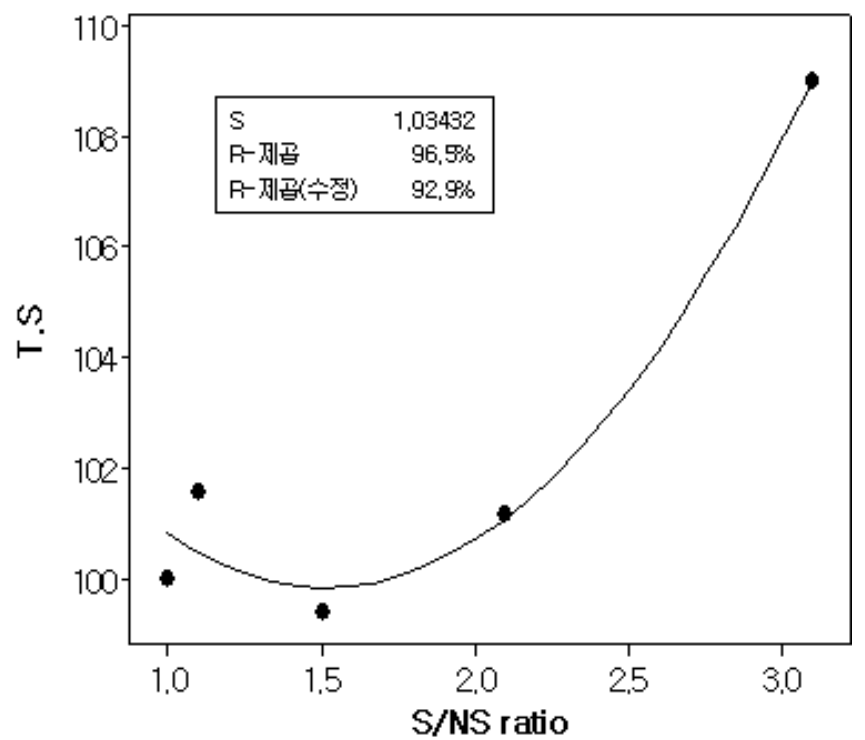

적합선 플롯

$E, B=110,2-14,55 S / N S$ ratio

$+4,50 \mathrm{~S} / \mathrm{NS}$ ratio $*+2$

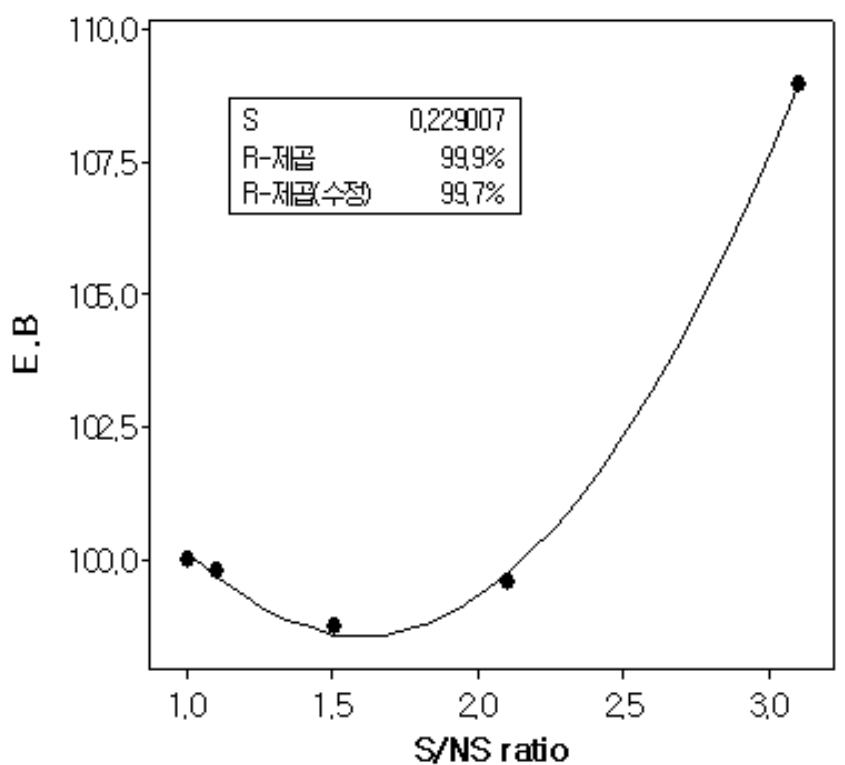

** The ratio of Sulfur / Accelerator $=2.0 / 0.65,1.8 / 0.85,1.6 / 1.05,1.40 / 1.25,1.30 / 1.3 ; * *$ DIN \& CUT/CHIP : The lower value, the better wear resistance; TS : Tensile strength, EB: elongation at break(EB)

Fig. 11. Relationship between the physical properties and sulfur/accelerator ratio (standard specimen is sample of sulfur/accelerator ratio $1.3 / 1.3,100 \%$ )

displayed a relatively simple crack pattern compared to the CV or hybrid cure system. Fig. 13 shows the relationship between wear properties and the relative X-link density. The cross-link density has little effect on the wear loss of the DIN and PICO results, but has a major effect on the cutting and chipping resistance.

When combining the test results of the cure system effect, the conventional cure system related to the ratio of the sulfur/accelerator (1.5-2.1), is applicable to compounds for the cutting and chipping resistance. On the other hand, a semi efficient cure system, which is related to the ratio of sulfur/ accelerator, $(<1.5)$, is suitable for compounds for wear resistance or the low rolling resistance compound of truck and bus radial.

\section{Conclusion}

The tread compound design concept of a truck tyre to overcome the trade-off between normal abrasion and cutting \& chipping resistance is as follows:

(1) The $300 \%$ stress of the tread compound should be between $90 \mathrm{kgf} / \mathrm{cm}^{2}$ and $135 \mathrm{kgf} / \mathrm{cm}^{2}$ for an un-paved road. This provides good cutting and chipping resistance, whilst maintaining the blow-out properties and minimizing the 

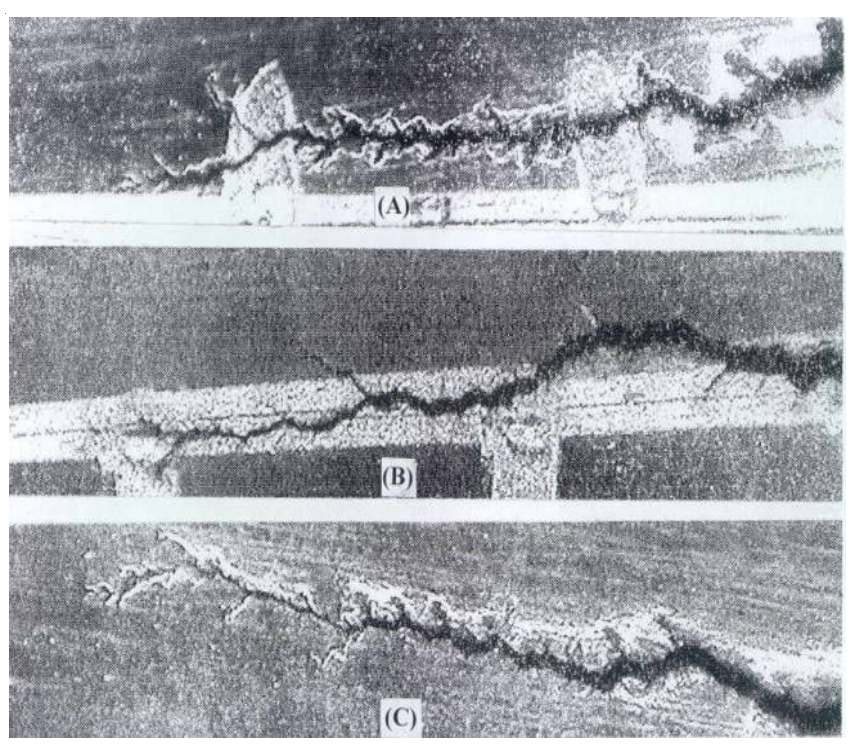

Fig. 12. Optical micrographs of the crack growth pattern under repeated strain condition with various the curing systems. (A) CV cure system, (B) Semi-EV system, (C) Hybrid cure system $\left(\sim \mathrm{CH}_{2} \mathrm{SxCH}_{2} \sim, \mathrm{X}: 1 \sim 3\right)$.

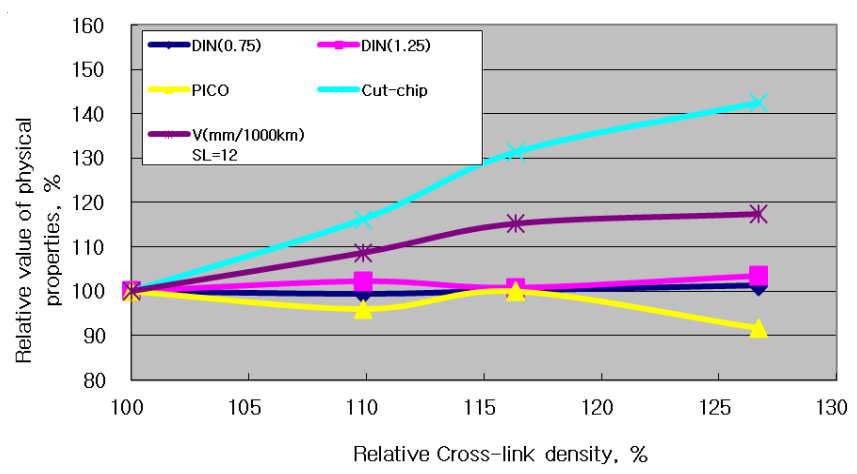

Fig. 13. Effects of the physical properties as a function of the X-link density in TBR tread compounds

fatigue wear resistance. On the other hand, the $300 \%$ stress of the tread compound for a paved road should be between 135 to $165 \mathrm{~kg} / \mathrm{cm}^{2}$ for good wear resistance. If the $300 \%$ stress is $>165 \mathrm{kgf} / \mathrm{cm}^{2}$, the tread area of the truck tyre showed good fatigue wear at the early times but cutting and chipping can progress easily if run on and off the roads at the same time.

(2) The recommended polymer base of a tread compound for an on and off road tyre should use a NR base for excellent fatigue and failure properties under harsh condition and a NR/ SBR blend for cutting resistance under low severity conditions.

(3) In silica/ black blend cured samples, the tensile strength, tear energy and intrinsic cut size appear to pass the maximum point corresponding to 10-20 phr silica compounds. The critical cut size for silica compounds is higher than that of black filled NR. Silica offers significant advantages in some applications that cannot be obtained with carbon black alone.

(4) The conventional cure system with a sulfur/accelerator ratio of 1.5-2.1, is applicable to compounds for cutting and chipping resistance. On the other hand, a semi-efficient cure system with sulfur/accelerator ratio, $<1.5$, can be applied to compounds for wear resistance or a low rolling resistance compound of truck and bus radial.

\section{ACKNOWLEDGEMENTS}

This study was carried out at the R\&D center of KUMHO TIRE Co., Korea (ROK). The paper is presented by the permission of Dr. Cho, Vice-President of KUMO R\&D Center.

\section{REFERENCES}

1. Y. Udagawa, 139th ACS rubber Division Meeting (May, 21-24, 1991).

2. Y. Udagawa and S. Kawakami, 138th ACS rubber Division Meeting (Oct, 1990)

3. Y. Uchiyama, Tire Sci. Technol., 22, 2 (1994).

4. E. Southern and A.G. Thomas, Rubber Chem. Technol., 52, 469 (1979).

5. J.T. Byers, Degussa Corp., Rubber World, vol. 218, September p. 38 (1998).

6. S.W. Hong, M.P. Ferrandino and J.A. Sanders, $150^{\text {th }}$ ACS Rubber Division Meeting (Oct, 1996).

7. R.S. Rivlin and A.G. Thomas, J. Polym. Sci., 10, 291 (1953).

8. S.S. Park, B.H. Park, K.C. Song and S.K. Kim, Polymer (Korea), 24, 220 (2000).

9. G.R. Hamed and H.J. Kim, Rubber Chem. Technol., 72, 895 (1999).

10. G.R. Hamed, Rubber Chem. Technol., 56, 244 (1983).

11. T. Kleiner and R. Schuster, ACS Rubber Division Meeting (Apr. 29May 1, 2002). 